\title{
Response to: Burnout and Associated Factors Among Medical Students in Uganda [Letter]
}

This article was published in the following Dove Press journal:

Advances in Medical Education and Practice

\section{Jin Stephen Lam \\ Pylin Parkes $\mathbb{D}$ \\ Susannah Wang}

Faculty of Medicine, Imperial College London, London, UK
Correspondence: Pylin Parkes

Faculty of Medicine, Imperial College London, London, UK

Email pylin.parkes 15@imperial.ac.uk

\section{Dear editor}

Kajjimu et al's study is the first to generate data on burnout prevalence among medical students in Uganda, hence playing an integral role in diversifying literature. $^{1}$ The study suggested multi-centre longitudinal studies for future research. Alongside this, we believe it would be useful to further explore the causes of burnout in this population.

Kajjimu et al assessed several factors associated with burnout, and only found it significantly associated with "choosing the $\mathrm{MBChB}$ [degree] willingly". There is literature that supports and refutes this association. ${ }^{2}$ Pagnin et al found that students who chose medicine due to death or illness of a relative had a higher rate of emotional exhaustion than other students. ${ }^{3}$ Additionally, Györffy et al found that lack of altruistic motivation for choosing medicine was a leading factor for burnout. ${ }^{4}$ Therefore, more in-depth research is required to understand why choosing a medicine career may lead to burnout in Ugandan medical students. We also feel it would be useful to explore whether this single factor was the cause of burnout in the study population, or if there were other factors that have not been evaluated.

Understanding the causative factors of burnout in Uganda could also improve the generalisability of Kajjimu et al's findings and inform future interventions. The study's results were inconsistent with reported burnout prevalence in other countries, such as Ethiopia and Spain, and the authors suggested that "socio-economic, political, health, and conflict-related stress factors" could have led to this. This was echoed by a recent review that found no discernible pattern between burnout and personal stressors, such as housing, relationships and academic studies, across 12 countries. ${ }^{5}$ The study also mentions its generalisability to other low- and middleincome countries; however, this is difficult to justify due to the high variations in burnout prevalence across countries and a lack of understanding of what led to these differences.

An in-depth understanding of the socio-economic, cultural and political landscape of the study area could help identify more causative factors of burnout and inform which targeted interventions may be effective in this setting. Then, applicability to other medical student communities of similar contextual background could be assessed. We suggest a qualitative study could be used to gather this data since it allows in-depth exploration of the reasons behind the students' answers, e.g. what are the reasons for "choosing MBChB willing", and why the other factors investigated were not significant. 
Medical students' well-being is crucial for not only keeping future doctors healthy, but also their patients. We value Kajjimu et al's contribution to the literature and look forward to reading future research into this topic.

\section{Disclosure}

The authors report no conflicts of interest in this communication.

\section{References}

1. Kajjimu J, Kaggwa M, Bongomin F. Burnout and associated factors among medical students in a public university in uganda: a cross-sectional study. Adv Med Educ Pract. 2021;12:63-75. doi:10.2147/AMEP.S287928
2. Njim T, Makebe H, Toukam L, et al. Burnout Syndrome amongst medical students in cameroon: a cross-sectional analysis of the determinants in preclinical and clinical students. J Psychiatry. 2019;2019: e4157574. doi: $10.1155 / 2019 / 4157574$

3. Pagnin D, De Queiroz V, Oliveira Filho M, et al. Burnout and career choice motivation in medical students. Med Teach. 2013;35 (5):388-394. doi:10.3109/0142159X.2013.769673

4. Győrffy Z, Birkás E, Sándor I. Career motivation and burnout among medical students in Hungary - could altruism be a protection factor? BMC Med Educ. 2016;16(1). doi:10.1186/s12909-016-0690-5

5. Molodynski A, Lewis T, Kadhum M, et al. Cultural variations in wellbeing, burnout and substance use amongst medical students in twelve countries. Int Rev Psychiatry. 2020:1-6.

Dove Medical Press encourages responsible, free and frank academic debate. The content of the Advances in Medical Education and Practice 'letters to the editor' section does not necessarily represent the views of Dove Medical Press, its officers, agents, employees, related entities or the Advances in Medical Education and Practice editors. While all reasonable steps have been taken to confirm the content of each letter, Dove Medical Press accepts no liability in respect of the content of any letter, nor is it responsible for the content and accuracy of any letter to the editor.

\section{Publish your work in this journal}

Advances in Medical Education and Practice is an international, peerreviewed, open access journal that aims to present and publish research on Medical Education covering medical, dental, nursing and allied health care professional education. The journal covers undergraduate education, postgraduate training and continuing medical education including emerging trends and innovative models linking education, research, and health care services. The manuscript management system is completely online and includes a very quick and fair peer-review system. Visit http://www.dovepress.com/testimonials.php to read real quotes from published authors. 